\title{
New Load Flow Method S-E Oriented For Large Radial Distribution Networks
}

\author{
H. M. Khodr , Member, IEEE, L. Ocque, J. M. Yusta , Member, IEEE, and, M. A. Rosa, Student Member, IEEE
}

\begin{abstract}
There is a growing interest in the electric utilities to raise their efficiency in the operation and design of transmission and distribution of systems. This work proposes a new, fast, robust and efficient method for the Load Flow solution, in balanced and unbalanced radial distribution systems. It is about a sequential method, based on the $S-E$ load flow algorithm devised for transmission networks by Zaborszky in 1981, which has been adapted to distribution systems, orienting the powervoltage $(S-E)$ iterations, to take advantage of the radial condition of the latter and extending it to handle unbalanced three-phase systems. The iterative process consists of progressively concentrating the load plus network losses at each node, starting from the farend ends nodes and moving toward the substation. Secondly, the nodal complex voltages are calculated from the substation toward the demand nodes, carrying on with this relatively simple procedure, till reaching convergence. The effectiveness of the algorithm is shown when comparing it against other methods widely used in the specialized literature. In particular it is tested against methods proposed by Ardvinson, Shirmohammadi, Ghosh and Das, Jovanovic and Cespedes. The here-in proposed methodology represents a valuable tool that substantially improves the state-of-the-art of the load flow.
\end{abstract}

Index Terms - Distribution System, Load Flow, S-E Oriented (Power and Voltage Oriented), Radial System.

\section{INTRODUCTION}

$\mathrm{N}$ owadays, with the opening of the electrical sector and its structural new divided on energy product and energy services, it made appear the needing have to developed competence among the businesses in the generation, transmission and especially distribution of electricity. Therefore, to each day is necessary to know quickly the load behavior and consequently the electrical parameters of the networks. In order to reach these objectives is required to know the state of the network, for all operation interval time. Thus, the businesses can employ the electric rate as a key factor in the load management, that is to say, penalizing with a greater rate to those consumers that they make use of the energy in hours of maximum demand, contributing to the overload of the network, and the entrance of inefficient generating plants in the system [38].

This work has been supported in part by Fundação para a Ciência e a Tecnologia Grant SFRH/ BPD/ 21035/ 2004. ${ }^{1}$

H. M. Khodr is with Instituto de Engenharia de Sistemas e Computadores (INESC Porto), Dr. Roberto Frias, 378 4200-465 Porto, Portugal on leave of Universidad Simón Bolívar, Aptdo.89000, Caracas, Venezuela. (e-mail: hkhodr@usb.ve)

J. M. Yusta is with Department of Electrical Engineering, Universidad de Zaragoza, Maria de Luna 3, E-50018 Zaragoza, Spain. (e-mail: jmyusta@unizar.es)
Inside an open market to the competence are presented to the different businesses the need to implement actions oriented the optimization of electric networks in search of minimum costs of operation guaranteeing adequate service with quality levels [15]. In order to achieve an optimization level of the networks is required the implementation of certain process, so much technical as well as organizing, whose prior step should be that of know the present state of the network in stationary state. It given this growing interest that exists currently among the electric utilities to enlarge its efficacy in the operation and distribution of the electric power, takes special attention the load flow solution of the distribution networks [22] [42].

The load flow to become possible to determine the conditions of stationary state of a power system for a specific generation and demand level [12]. The fundamental task of a load flow algorithm is to obtain the voltages in the bus and the power flows by the lines since the knowledge of the network topology, parameters such as impedances, loads and sources (generation) [38].

Several works have been developed in the load flows research area to distribution networks with different approaches of algorithms solutions and that verifying difficulties when apply on real dimensions systems and normally consumes high time and computational effort. On the other hand these algorithms do not permit to consider one of the main characteristics of the distribution networks like the unbalance existing among the phases. Therefore, it is necessary to carry out efforts to develop new algorithms that improve the actual methods [25].

The classic algorithms of Newton Raphson and GaussSeidel have been the base of the generic methods for the load flow solution, especially in transmission networks [5] [6] [10] [21] [26]. Nevertheless, according to the specialists their application in the case of the distribution networks has not been very efficient due mainly to the characteristics networks to be generally of radial structure and to present a high relation $(\mathrm{R} / \mathrm{X})$ of lines, when we are making a comparison with the transmission networks [12] [14] [16] [17] [30]. Different research has suggested methods for the solution of loads flow to distribution networks with a high relation $\mathrm{R} / \mathrm{X}$ [27] [28] [29] [41] [42]. In fact, it has carried to development of algorithms specialized for distribution networks and with characteristics of the greater simplicity has been obtained efficiency in the solution of load flow problem for the Distribution Systems [17].

There are several efficient methods published recently [7] [12] [14] [17] [23] [42]. They are iterative methods, some them need the most computing time, requires evaluating the complex matrix, and in some cases don't insure convergence. 
In this paper, is presented a fast and simple method for solving radial single-phase and three-phase distribution networks called S-E Oriented Method. This is a sequential method that uses only two calculation steps. The proposed algorithm can be easily programmed based upon a simple formulation.

\section{THE PROPOSED METHOdOLOGY}

The proposed methodology for the solution of the load flow problem in distribution networks, is based on the load flow algorithm S-E oriented for transmission networks, proposed by Zaborszky in 1981 [39], which was adapted to distribution systems orienting the iterations power-tension (S-E), to take advantage of the radial characteristics of these and extended for applied to unbalanced three phase distribution systems.

The proposed method S-E graph oriented for the solution of the load flow problem in distribution networks, consists of a sequential method in which proceeds to determine in a first step the losses in the branches and the active and reactive power equivalent in the same one, supposing in the first iteration known values for the tensions in the nodes (= $1 \mathrm{PU})$.

In the second step proceeds to calculate the nodes tensions (module and angle), assuming as you known the values of power calculated in the first step. Then it proceeds to repeat the first step, but in this second iteration proceeds to calculate the losses assuming the tensions calculated in the second step of the first iteration until comply the convergence criterion.

\section{A. Representation of the network}

One of the characteristics of the proposed algorithm is the fact that does not require of a numbering of nodes and branches by layers. For this algorithm the nodes and the branches can be numbered without a predetermined order, characteristic that does it more flexible and strong.

In the revised algorithms in the literature the numbering of the nodes and branches should be performed for layers, in a similar way of the model proposed by Shirmohammadi [32], being had that renumbering the nodes and the branches in the systems whose dates not possess this structure.

\section{B. Proposed Algorithm for three phase balanced systems}

For the solution of the load flow problem in three phase balanced distribution networks, an algorithm be planted utilizing the single phase equivalent of the network. For each iteration of the methodology, is carried out the calculation of the equivalent power and losses, concentrated on each branch, tension is assumed 1 p.u. in all the buses of the system in the first iteration. After concentrating the power in each bus, the algorithm proceeds to calculation of the currents and voltages in each node, leaving from the power calculated in the first step.

The calculation of the power concentrated on each branch, is carried out from the following equations:

$$
\begin{gathered}
P_{E i}=P_{\text {Loadi }}+P_{\text {Lossi }}+P_{E C i} \\
Q_{E i}=Q_{\text {Loadi }}+Q_{\text {Lossi }}+Q_{E C i}
\end{gathered}
$$

The losses in each branch are calculated through the following equations:

$$
\begin{aligned}
& P_{\text {Lossi }}=\left(\frac{S_{i}}{V_{o i}}\right)^{2} \cdot R_{L i}, i=n, n-1, \ldots \ldots 1 \\
& Q_{\text {Lossi }}=\left(\frac{S_{i}}{V_{o i}}\right)^{2} \cdot X_{L i}, i=n, n-1, \ldots \ldots 1
\end{aligned}
$$

Where,

$P_{E C i}, Q_{E C i}$ : Are the equivalent active and reactive load of the branches fed by the branch $\mathrm{i}$.

$P_{\text {Lossi }}, Q_{\text {Lossi }}:$ Active and Reactive losses of the branches fed by the branch $\mathrm{i}$.

$P_{\text {Loadi }}, Q_{\text {Loadi }}:$ Active and Reactive load at the node i.

$S_{i}$ : Apparent power at the node i.

$V_{0 i}$ : Voltage of the node $\mathrm{i}$ in the first iteration.

$R_{L i}$ : Resistance of the branch i.

$X_{L i}$ : Reactance of the branch i.

$n$ : Number of the branches.

At each iteration of the algorithm totals all the losses of the system and the power that should be supplied by the source. The total losses and the load of the source are calculated by the following equations:

$$
\begin{aligned}
& P_{T}=\sum P_{\text {lossi }}+\sum P_{E C i} \\
& Q_{T}=\sum Q_{\text {lossi }}+\sum Q_{E C i}
\end{aligned}
$$

Once known the concentrated power on the receiver extreme of each branch, the branch currents and the nodal tensions are calculated through the following equations:

$$
\begin{gathered}
I_{i}=\left[\frac{P_{E i}+J \cdot Q_{E i}}{V_{E i}}\right]^{*} \\
V_{R i}=V_{E i}-I_{i} \cdot\left(R_{i}+J \cdot X_{i}\right)
\end{gathered}
$$

$V_{E i}$ : Voltage of the source node of the Branch $i$.

$V_{R i}$ : Voltage of the load node of the branch i.

These calculations are carried out successively until the convergence criterion is comply, that is, that the difference in voltage between the previous iteration and the present one be smaller to a certain defined value, for each nodes.

The S-E oriented Method is applied to single-phase and three-phase radial balanced and unbalanced networks.

\section{Assumptions}

The substation Voltage $\left(V_{0}\right)$, Load Demand at bus $\mathrm{i}$ $\left(S_{i}=P_{i}+j \cdot Q_{i}\right)$, and impedances of distribution lines $\left(Z_{i}=R_{i}+j \cdot X_{i}\right)$ are specified. The systems can represent by their equivalent single line diagram.

The network is simulated in the program by means of nodes (load concentration in a point of the network) and branches (section of conductor between two nodes). The nodes and branches numbering is the same suggested by Shirmohammadi [6]. 


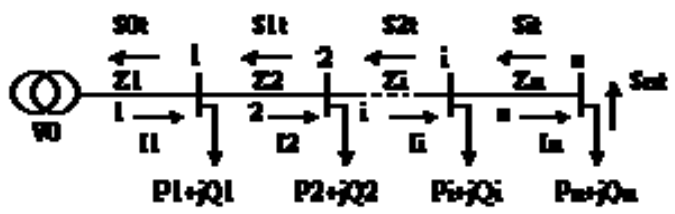

Fig. 1: Single Line Diagram

\section{Algorithm Solution}

The substation Voltage $V_{0}$, Load Demand at bus i $S_{i}=P_{i}+j \cdot Q_{i}$,

Considering the distribution network of the Figure 1:

Step1: Losses and equivalent Power Calculation

The branches current used in the step 1 are calculated considering the nodes voltage equal to the substation voltage. The power losses are calculated from the last branches towards the source:

$$
\begin{aligned}
\Delta S i t & =I i^{2} R n+j I i^{2} X n \\
\Delta S 2 t & =I 2^{2} R i+j I 2^{2} X i \\
\Delta S 1 t & =I 1^{2} R 2+j I 1^{2} X 2 \\
\Delta S 0 t & =I 0^{2} R 1+j I 0^{2} X 1
\end{aligned}
$$

The equivalent power is calculated as:

$$
\begin{gathered}
\text { Snt }=P n+j Q n \\
\text { Sit }=\Delta S i t+P n+j Q n \\
S 2 t=\Delta S 2 t+P i+j Q i+P n+j Q n \\
S 1 t=\Delta S 1 t+P 2+j Q 2+P i+j Q i+P n+j Q n \\
S n t=\Delta S 0 t+P^{\prime} 1+j Q 1+P 2+j Q 2+P i+j Q i+P n+j Q n
\end{gathered}
$$

Step 2: Voltage Magnitudes

The branches current used in the step 2 are calculated considering the equivalent power obtained from step 1.The voltage magnitudes are calculated from the source towards the last branches:

$$
\begin{aligned}
& V 1=V 0-(I 1 R 1+j I 1 X 1) \\
& V 2=V 1-(I 2 R 2+j I 2 X 2) \\
& V i=V 2-(I i R i+j I I X i) \\
& V n=V i-(I n R n+j I n X n)
\end{aligned}
$$

Where,

$\Delta$ Sit : Power loss injection at node i.

Sit : Power injection at node i.

$\mathrm{Si} \quad$ : Load Demand at bus i.

Ii : Branch current that flow through branch i.

$\mathrm{Zi}$ : Impedance of branch $\mathrm{i}$.

Step 3: New losses calculations for new voltage value In this step the new branches current are calculated considering the nodes voltage calculated in the step 2 . The new losses power is calculated equal the step 1 , but in this case using the calculated voltage in the step 2.

Step 4: Calculations of new voltage magnitudes

Repeat the step 2 using the new values calculated.

This process is repeated until the convergence is comply or the $V^{k}-V^{k+1} \leq \varepsilon$.

The Flowchart of the proposed method is given in Fig. 3.

\section{TESTING}

\section{A. Case $N^{\circ}$ 1: 28-bus test Distribution network}

Real system of $11 \mathrm{kV}$ and a power base of $100 \mathrm{kVA}$, whose single phase diagram is shown in the fig. 2 and the data, are shown in the Table I.

Five existing load Flow algorithms of the literature were selected, which will be employees like the boss of comparison to validate the proposed method. The advantages were studied and comparative disadvantages of the methods exposed previously, taking into account the experiences reported by the specialists in the literature.

The chosen algorithms are: the method proposed by Shirmohammadi [32], Ardvinson [38], Ghosh and Das [17], Jovanovic [23] and Céspedes [7]. These methods were selected as methods of reference for comparison effects of the behavior by the following reasons:

- In the determined cases of radial distribution networks, the algorithms of Gauss-Seidel and Newton Raphson not convergence is guaranteed.

- With the Gauss-Seidel algorithm is required of greater iterations number and computation time to arrive at the solution that with other algorithms.

- The algorithms of Ardvinson, Ghosh and Das, Shirmohammadi, Jovanovic and Céspedes present good convergence rapidity, simplicity in calculations and facility of programming, when they apply to balanced radial three phase distribution networks.

They are very efficient methods and they do not require carrying out complex operations with Matrix, facilitating the programming and the time of execution, except for the method proposed by Jovanovic that requires working with Matrix.

These five methods and the proposed in the present work, they were programmed in a same platform in Matlab and test in the solution of five different magnitudes distribution systems, 12 nodes [43], 23 nodes [13], 28 nodes [28], 69 nodes [2] [3] and 201 nodes [4], whose results are found reported in the literature. The results obtained for each one of the studied systems; also they were validated with a commercial program.

To demonstrate the effectiveness of the proposed algorithm, was compared with other algorithms of the specialized literature, the method proposed by Ardvinson [38], Shirmohammadi [32], Ghosh and Das [17], Jovanovic [23] and Céspedes [7], these methods are planned utilizing the same platform of programming and evaluated with the same criterion of convergence. In this phase the behavior of the algorithms was evaluated for five systems taken of literature verifying number of iterations and time of execution for each one of the methodologies. The criterion of convergence utilized corresponds to a $\varepsilon=0.0001$ p.u. All information regarding of iteration number and executing time are shown in the Fig. 4 and 5.

In the Table III, is observed that the five methodologies give similar results, presenting a variation in the quarter decimal, the methodologies of Jovanovic and Ardvinson alone for the farthest bus away of the substation. 
The Fig. 4 and Fig. 5, sample a summary of the iterations number and the execution time for each algorithm to be tested with the 28 nodes system.

It is observed in the Table III, the six methodologies are converged with equal iterations number and the proposed methodology presented the solution in smaller time.

TABLE I

DATA OF 28-NODE DISTRIBUTION NETWORK

\begin{tabular}{|c|c|c|c|c|c|}
\hline Send Bus & End Bus & $\mathbf{R}(\Omega)$ & $\mathbf{X}(\Omega)$ & $P(k W)$ & $Q$ (kVAr) \\
\hline 1 & 2 & 0.12648 & 0.05263 & 140 & 90 \\
\hline 2 & 3 & 0.15463 & 0.06579 & 80 & 50 \\
\hline 3 & 4 & 0.09486 & 0.03947 & 80 & 60 \\
\hline 4 & 5 & 0.06374 & 0.02632 & 100 & 60 \\
\hline 5 & 6 & 0.25296 & 0.10526 & 80 & 50 \\
\hline 6 & 7 & 0.18972 & 0.07895 & 90 & 40 \\
\hline 7 & 8 & 0.10119 & 0.04211 & 90 & 40 \\
\hline 8 & 9 & 0.18972 & 0.07895 & 80 & 50 \\
\hline 9 & 10 & 0.25296 & 0.10526 & 90 & 50 \\
\hline 10 & 11 & 0.19108 & 0.05402 & 80 & 50 \\
\hline 11 & 12 & 0.09554 & 0.02701 & 80 & 40 \\
\hline 12 & 13 & 0.28663 & 0.08103 & 90 & 50 \\
\hline 13 & 14 & 0.28663 & 0.05942 & 70 & 40 \\
\hline 14 & 15 & 0.21019 & 0.05402 & 70 & 40 \\
\hline 15 & 16 & 0.19108 & 0.08103 & 70 & 40 \\
\hline 16 & 17 & 0.28663 & 0.05402 & 60 & 30 \\
\hline 17 & 18 & 0.19108 & 0.05402 & 60 & 30 \\
\hline 2 & 19 & 0.23886 & 0.06753 & 70 & 40 \\
\hline 19 & 20 & 0.09554 & 0.02701 & 50 & 30 \\
\hline 20 & 21 & 0.19108 & 0.05402 & 50 & 30 \\
\hline 21 & 22 & 0.34395 & 0.09724 & 40 & 20 \\
\hline 3 & 23 & 0.37339 & 0.07023 & 50 & 30 \\
\hline 23 & 24 & 0.21019 & 0.05942 & 50 & 20 \\
\hline 24 & 25 & 0.38217 & 0.10804 & 60 & 30 \\
\hline 6 & 26 & 0.19108 & 0.05402 & 40 & 20 \\
\hline 26 & 27 & 0.09554 & 0.02701 & 40 & 20 \\
\hline 27 & 28 & 0.09554 & 0.02701 & 40 & 20 \\
\hline
\end{tabular}

TABLE II

REAL AND REACTIVE POWER LOSSES

\begin{tabular}{|c|c|c|}
\hline Algorithm & Iterations Number & Execution Time (Sec.) \\
\hline Ghosh and Das & 2 & 0.22 \\
\hline Shirmohammadi & 2 & 0.28 \\
\hline Céspesdes & 2 & 0.49 \\
\hline Jovanovic & 2 & 0.44 \\
\hline Ardvinson & 2 & 0.6 \\
\hline Proposed Method & 2 & 0.19 \\
\hline
\end{tabular}

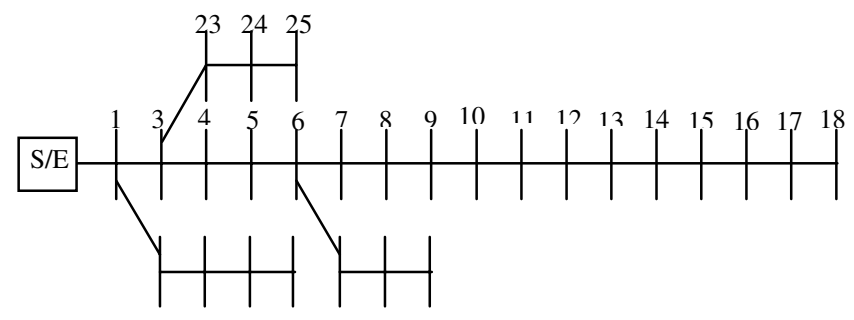

$\begin{array}{lllllll}19 & 20 & 21 & 22 & 26 & 27 & 28\end{array}$

Fig.2. 28-Bus single phase diagram

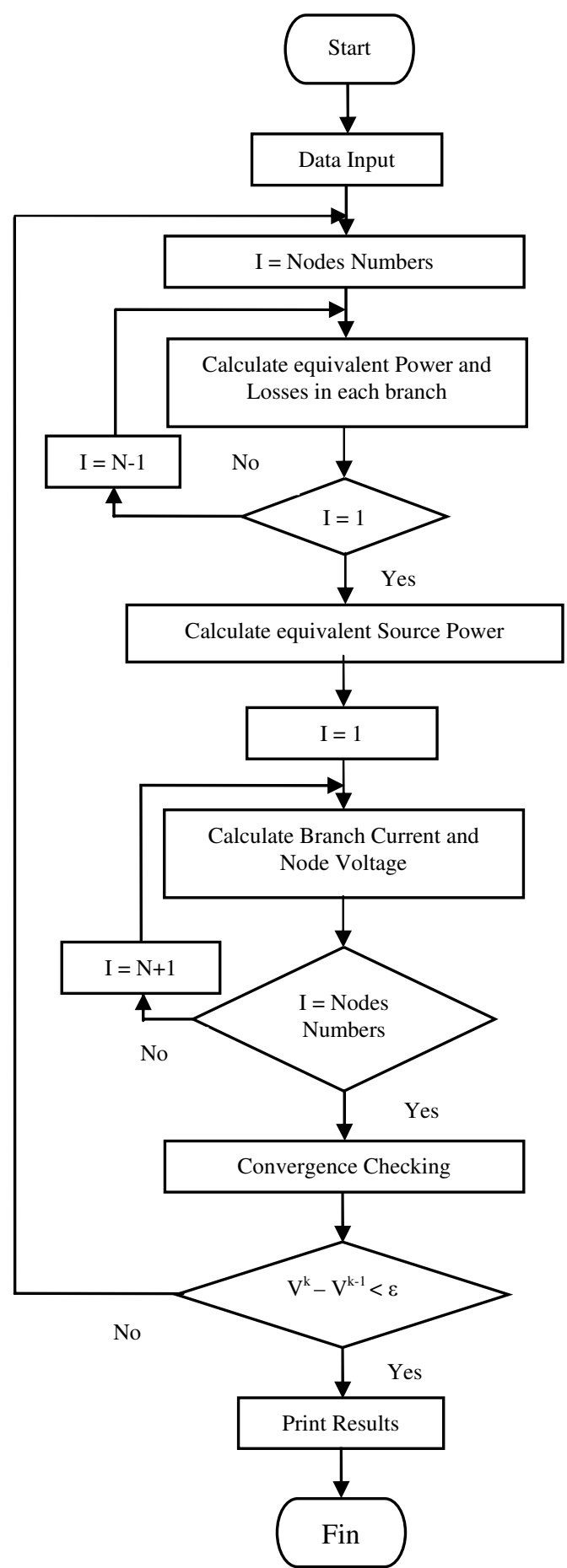

Fig. 3: Flowchart for load flow algorithm 
TABLE III

VOLTAGE NODES WITH THE DIFFERENT METHODOLOGY

\begin{tabular}{|c|c|c|c|c|c|c|}
\hline Node & Ghosh and Das & Céspedes & Shirmohammadi & Jovanovic & Ardvinson & Proposed Methodology \\
\hline 1 & 1.0 & 1.0 & 1.0 & 1.0 & 1.0 & 1.0 \\
\hline 2 & 0.9998 & 0.9998 & 0.9998 & 0.9998 & 0.9997 & 0.9998 \\
\hline 3 & 0.9995 & 0.9995 & 0.9995 & 0.9995 & 0.9995 & 0.9995 \\
\hline 4 & 0.9994 & 0.9994 & 0.9994 & 0.9993 & 0.9993 & 0.9994 \\
\hline 5 & 0.9993 & 0.9993 & 0.9993 & 0.9992 & 0.9992 & 0.9993 \\
\hline 6 & 0.9990 & 0.9990 & 0.9990 & 0.9989 & 0.9989 & 0.9990 \\
\hline 7 & 0.9988 & 0.9988 & 0.9988 & 0.9986 & 0.9987 & 0.9988 \\
\hline 8 & 0.9987 & 0.9987 & 0.9987 & 0.9986 & 0.9986 & 0.9987 \\
\hline 9 & 0.9986 & 0.9986 & 0.9986 & 0.9985 & 0.9985 & 0.9986 \\
\hline 10 & 0.9984 & 0.9984 & 0.9984 & 0.9983 & 0.9983 & 0.9984 \\
\hline 11 & 0.9983 & 0.9983 & 0.9983 & 0.9982 & 0.9982 & 0.9983 \\
\hline 12 & 0.9983 & 0.9983 & 0.9983 & 0.9981 & 0.9981 & 0.9982 \\
\hline 13 & 0.9981 & 0.9981 & 0.9981 & 0.9980 & 0.9980 & 0.9981 \\
\hline 14 & 0.9980 & 0.9980 & 0.9980 & 0.9979 & 0.9979 & 0.9980 \\
\hline 15 & 0.9980 & 0.9980 & 0.9980 & 0.9979 & 0.9979 & 0.9980 \\
\hline 16 & 0.9980 & 0.9980 & 0.9980 & 0.9978 & 0.9978 & 0.9980 \\
\hline 17 & 0.9979 & 0.9979 & 0.9979 & 0.9978 & 0.9978 & 0.9979 \\
\hline 18 & 0.9979 & 0.9979 & 0.9979 & 0.9978 & 0.9978 & 0.9979 \\
\hline 19 & 0.9997 & 0.9997 & 0.9997 & 0.9997 & 0.9997 & 0.9997 \\
\hline 20 & 0.9997 & 0.9997 & 0.9997 & 0.9997 & 0.9997 & 0.9997 \\
\hline 21 & 0.9997 & 0.9997 & 0.9997 & 0.9997 & 0.9997 & 0.9997 \\
\hline 22 & 0.9997 & 0.9997 & 0.9997 & 0.9996 & 0.9996 & 0.9997 \\
\hline 23 & 0.9994 & 0.9995 & 0.9994 & 0.9994 & 0.9994 & 0.9994 \\
\hline 24 & 0.9994 & 0.9994 & 0.9994 & 0.9994 & 0.9994 & 0.9994 \\
\hline 25 & 0.9994 & 0.9994 & 0.9994 & 0.9994 & 0.9994 & 0.9994 \\
\hline 26 & 0.9990 & 0.9990 & 0.9990 & 0.9989 & 0.9989 & 0.9990 \\
\hline 27 & 0.9990 & 0.9990 & 0.9990 & 0.9989 & 0.9989 & 0.9990 \\
\hline 28 & 0.9990 & 0.9990 & 0.9990 & 0.9989 & 0.9989 & 0.9990 \\
\hline
\end{tabular}

\section{CONCLUSION}

This work presented a new methodology for the solution of the load flow in radial distribution networks, which turned out to be powerful, fast and efficient, as well as a simple formulation and easy to programming. As before mentioned this method was tested with five different distribution systems, 12-buses, 23-buses, 28-buses, 69-buses and 201-buses commonly used in the technical literature.

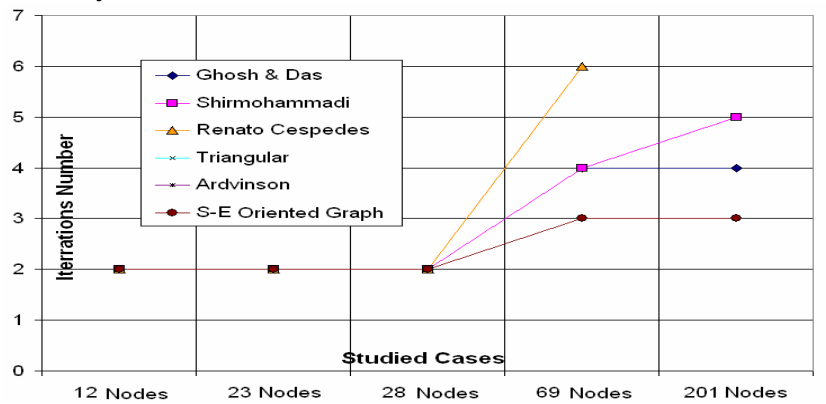

Fig. 4: Iterations Number for the five studied cases

The obtained results were equal to them reported by the authors of the works of which they were extracted the systems of test, and besides they were validated with a commercial program [43] to resolve load flows in distribution systems.

The proposed methodology always converged al turned out expected, in a smaller time that the other methodologies, to a $50 \%$ smaller, and in a smaller number of iterations.
These affirmations were more notable for the cases of greater dimension, 69 nodes and 201 nodes, in which there were algorithms that did not converge, being concluded that the proposed methodology can be utilized to solve the load flow problem in large distribution systems and that consumes small computational time and small iterations number.

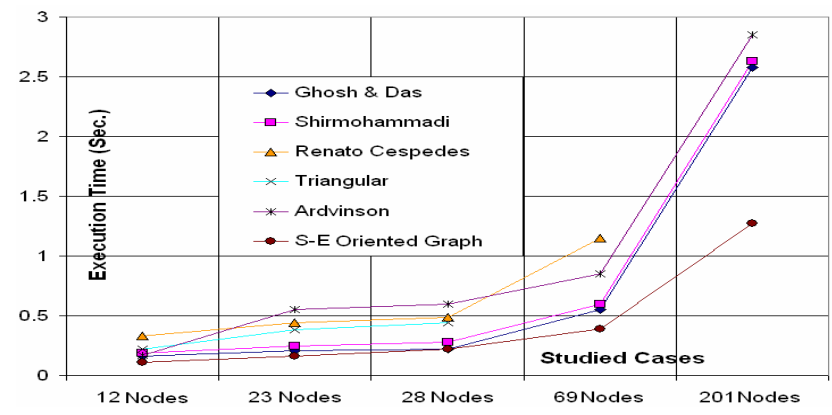

Fig. 5: Execution Time for the five studied cases

\section{REFERENCES}

[1] O. Alsac and B. Stott, "Optimal load flow with steady-state security," IEEE. PES Summer Meeting. 1973, pp 745-751.

[2] M. Baran and F. Wu, "Network reconfiguration in distribution systems for loss reduction and load balancing," IEEE Trans. PWRD. vol. 1, 1989, pp. 1401-1407.

[3] M. Baran and F. Wu, "Optimal sizing of capacitor placed on a radial distribution system," IEEE Trans. PWRD. vol. 1. 1989, pp. 735-743. 
[4] J. L. Bernal, "Genetic Algorithm application on Distribution System Optimal Design", PhD Thesis - Zaragoza University, Spain 1998 (Original Write on Spanish Language).

[5] K. Behnam-Guilani, "Fast decoupled load flow: the hybrid model," IEEE Trans. Power System. vol. 3. 1988, pp 734-741.

[6] K. Birt, J. Graffy and J. McDonald, "Three phase load flow program," IEEE Trans. PAS. PAS-95. 1976, pp. 59-64.

[7] R. Cspedes, "New method for the analysis of distribution network," IEEE Trans. PWRD. vol. 5. 1990, pp. 391-396.

[8] S. Chang and V. Brandwajn, "Adjusted solution in fast decoupled load flow," IEEE Trans. Power System. vol. 3. 1988, pp 726-733.

[9] C. cheng and D. Shirmohammadi, "A three phase power flow method for real time distribution system analysis," IEEE Trans. Power System. vol. 10. 1995, pp 671-679.

[10] T. Chen K. Hwang, P. Kotas and E. Chebli, "Distribution system power flow analysis - a rigid approach, " IEEE Trans. PWRD. vol. 6. 1991, pp. 1146-1152.

[11] T. Chen, M. Chen, T. Inoue, P. Kotas and E. Chebli, "Three phase cogenerator and transformer for distribution system analysis," IEEE Trans. PWRD. vol. 6. 1991, pp 1671-1678.

[12] H. Chiang, and Hsiao, "A decoupled load flow method for distribution power networks: algorithms, analysis and convergence study," Electrical Power \& Energy Systems, 1991, 13 (3) pp. 130-138.

[13] Y. da Silva, J. di Girolamo, and A. Ferreira, "Overhead Power Lines of the Distribution Systems Optimization on Petroleum Base", International Conference of the Andina Area IEEE, 1999, pp. 967-972. (Original Write on Spanish Language).

[14] D. Das, H. Nagi, and D. Kothari, "Novel method for solving radial distribution networks," IEE Proc. General Transm. Distribution, vol. 141, No. 6, 1994, pp 291-297.

[15] P. de Oliveira., "Optimal Manager Energy Price on Distribution System to Open Energy Market", MSc Thesis, Simón Bolivar University, Venezuela 2002. (Original Write on Spanish Language).

[16] P. Garcia, J. Pereira, S. Carneiro, V. da Costa, and N. Martins, "Three phase power flow calculation using the current injection method," IEEE Trans. Power System, vol. 15, 2000, pp. 508-514.

[17] S. Gosh and D. Das, "Method for load flow solution of radial distribution networks," IEE Proc. General Transm. Distribution, vol. 146, No.6, 1999, pp. 641-647.

[18] GOMEZ A., ROMERO E. "Reliable Load Flow Technique for Radial Distribution Network", IEEE Trans. Power System Vol. 14. 1999, pp 1063-1069.

[19] J. Gómez, "Ant Colony Algorithm applied to Optimal Plan of Network Distribution”, MSc Thesis, Simón Bolivar University, Venezuela 2001. (Original Write on Spanish Language).

[20] S. Goswami, "Distribution system planning using branch exchange techniques," IEEE Trans. Power System vol. 12. 1997, pp 718-723.

[21] S. Iwamoto and Y. Tamura, "A load flow calculation method for illconditioned power system," IEEE Trans. 1981. PAS-100, pp. 17361741 .

[22] G. Jasmon and L. Lee, "Stability of load flow techniques for distribution system voltage stability analysis," IEE Proceedings, vol. 138, No. 6. 1991, pp. 479-484.

[23] S. Jovanovic and F. Milicevic, "Triangular distribution load flow," IEEE. Power Engineering Review, 2000, pp. 60-62.

[24] W. Kersting, "A method to teach the design and operation of a distribution system," IEEE Trans. 1984. PAS-103, pp. 1945-1952.

[25] KIM B., BALDICK R. "A Comparison of Distributed Optimal Power Flow Algorithms", IEEE Trans. Power System Vol. 15. 2000, pp 599604

[26] G. Luo and A. Semlyen, "Efficient load flow for large meshed networks," IEEE Trans. Power System vol. 5. 1990, pp 1309-1315.

[27] A. Monticelli, A. Garcia and O. Saavedra, "Fast decoupled load flow: hypothesis, derivations, and testing," IEEE Trans. Power System vol. 5. 1990, pp. 1425-1431.

[28] H. Nguyen, "Newton Raphson method in complex form," IEEE Trans. Power System vol. 12, 1997, pp. 1355-1359.

[29] D. Popovic, R. Ciric, G. Svenda and Z. Gorecan, "Comparison of different algorithms for distribution network analysis," UPEC. 1997, pp. 182-185.

[30] D. Rajicic, A. Bose, "A modification to the fast decoupled power flow for networks with high R/X ratios," IEEE Trans. Power System vol. 2. 1988, pp 743-746.
[31] M. Sachdev and T. Medicherla, "A second order load flow techniques," IEEE Trans. 1977, PAS-96, pp. 189-195.

[32] D. Shirmohammadi, H. Howg, A Semlyen and A. Luo, "A compensation based power flow for weakly meshed distribution and transmission network," IEEE Trans. Power System vol. 3. 1988, pp. 753-762.

[33] A. Stankovic andf M. Calovic, "Three phase graph oriented algorithm for the steady state security enhancement distribution networks," IEEE Trans. PWRD. vol. 4. 1989, pp. 539-544.

[34] W. Stevenson and J. Grainger, "Power System Analysis", Mc Graw Hill, 1996, pp. 309-357.

[35] B. Stott and O. Alsac, "Fast decoupled load flow," IEEE. PES Summer Meeting. 1973, pp. 859-867.

[36] A. Tripathy, S. Durga, O. Malik and G. Hope, "Load flow solution for ill-conditioned power system by newton-like method," IEEE Trans. PAS 1982. PAS-101, pp. 3648-3657.

[37] N. Vempati, R. Shoults, M. Chen and L Schwobel, "Simplified feeder modeling for load flow calculations," IEEE Trans. Power System vol. PWRS-2, 1987, pp. 168-174.

[38] L. Willis, "Power distribution planning reference book," Text, editorial Marcel Dekker, 1997.

[39] F. Wu, "Theoretical study of the convergence of the fast decoupled load flow," IEEE Trans. PAS, 1977. PAS-96, pp. 268-275.

[40] J. Zaborszky and M. Ilic-Spong, "A different approach to load flow," Washington University, Department of System Science and Mathematics, Department of Energy Project No. ED-78-D-01-3090, 1981.

[41] F. Zhang and C. Cheng, "A modified newton method for radial distribution system power flow analysis," IEEE Trans. Power System vol. 12, 1997, pp. 389-397.

[42] R. Zimmerman and H. Chiang, "Fast decouple power flow for radial distribution system," IEEE Trans. Power System vol. 10, 1995, pp. 2045-2051.

[43] H. M. Khodr and A. J. Urdaneta, "Operational Assessment of the Morichal (P. D. V. S. A) Distribution System", Simón Bolivar University, Venezuela 2000. (Original Write on Spanish Language).

\section{BIOGRAPHIES}

H. M. Khodr (M'99), received the Ph.D., M.Sc. and B.Sc. degrees in Electrical Engineering from the José Antonio Echeverría Higher Polytechnic Institute (ISPJAE) in 1997 and 1993 respectively.

$\mathrm{He}$ is a Professor of Electrical Engineering at Universidad Simón Bolívar, Caracas, Venezuela. Presently, he is in a research stage at INESC Porto, Portugal. His current research activities are concentrated in the planning, operation and economics of electrical power systems.

L. Ocque received the electrical engineering degree from Instituto Universitario de las Fuerzas Armadas Nacionales (IUPFAN) in 1997 and the M.Sc. degree in electrical engineering from Universidad Simón Bolívar (USB), Caracas, Venezuela, in 2003.

Currently, he is a Project Engineer with the Instituto de Energía (INDENEUSB). He was with the Engineering Department at C.V.G. Electrificación del Caroní (EDELCA), Caracas, Venezuela.

J. M. Yusta (M’01) received the Industrial Engineer degree in 1994 and Ph.D. degree in 2000 from the Centro Politecnico Superior of the Universidad de Zaragoza, Spain.

$\mathrm{He}$ is Professor of Electrical Engineering and Vicedean of the Faculty of Engineering of the Universidad de Zaragoza. He is also head of the research group Electric Power Strategic Management (Ge3). He was Associate Professor at the Faculty of Engineering ICAI of the Universidad Pontificia Comillas from 1994 to 2002. His research interest includes technical and economic issues of electrical distribution systems.

M. A. da Rosa received the engineer degree in 1998 from the Pontifical Catholic University of Rio Grande do Sul, Brazil. He received at 2001 the title of Specialist at Distribution System Planning from the Makenzie University of São Paulo, Brazil and received MSc degree in 2003 from the PUCRS

Currently, is a Ph.D Student at Porto University and developed his activities in INESC Porto. He is Assistance Professor on the PUCRS University and His research interests include Power System Reliability and Artificial Intelligent Agent. 